\title{
The Culture of Mnemosyne: \\ Open book assessment and the theory and practice of legal education
}

\author{
Dr Paul Maharg
}

The concept of open book assessment is inherently controversial, not least because it contradicts a basic condition of examinations, one so basic to the event that we rarely question it: the single confrontation of examinee with exam question, the element of isolated and unaided struggle - Jacob wrestling with the mysterious Other. Surely it is cheating to allow texts into an exam-hall? What is the point of the exercise then?

This question has been posed in the field of educational theory. As the research there shows, assessment and learning have a complex and symbiotic relationship. In one study, for instance, a medical faculty altered its assessment procedures in order to change the factual learning of students to clinical learning, with very positive results (Newble \& Jaeger, 1983). In another, a change of assessment form from multiple-choice to essay then back again clearly demonstrated the effect that such a shift has upon student learning, turning superficial surface learning to deep learning and back to surface learning again (Thomas, 1986, quoted in Entwistle, 1992, p.39). These and other studies prove that the effect assessment has upon student learning is crucial and that, more particularly, changing the form of assessment changes students' learning patterns.

As a result of this and much more research which we shall consider below, I would argue that the question as to the purpose of open book examination requires to be answered on three levels. First of all, it involves scrutinising the learning objectives and teaching methods adopted in any particular course, and considering these together with matters such as course administration. Second, and at a deeper level, open book assessment sometimes involves us 
in reconsidering our models of the learning process; and our attitudes towards professional practice. A third, perhaps most fundamental issue, is raised in programmes of study where there are assessment criteria stipulated by professional regulatory bodies. In these circumstances the introduction of open book assessment opens up the whole relationship of theory to practice, in both educational and legal practice. What effect do the educational theories of professional bodies have on assessment practices? In this article I shall use the example of open book examinations as a type of 'critical incident' to help us analyse the complex relationship between theory and practice, and the implications of this relationship for effective legal education. ${ }^{1}$

\section{Open book exams: the literature}

The open book examination is of course not a new form of assessment. In an illuminating article John Francis (1982) reviewed the literature dealing with its effectiveness. He found that students' results were consistent over a wide spectrum of skills in different subject areas. Generally, he found that the advantages of open book regimes included the following points:

- students relied less on rote learning

- their anxiety about an examination was reduced

- factual knowledge was still learned

- learning occurred during the exam

The main disadvantages were -

- examinees lost time in the exam using the materials

- learning of the materials was reduced

- irrelevant answers

Francis also reports that some studies show no difference in achievement levels between open book and traditional examinations, and attributed this to the fact that in many studies the open book examination questions 'were not designed to exploit the advantages of the open-book situation' (1982, p.15). He quotes other studies which show that weaker candidates performed better in open book than in traditional examinations, and that open book assessment assisted students' recall more than their ability to deploy higher skills; but Francis points out that these results may have occurred because those studies used multiple choice examinations which assessed factual knowledge. He notes that many of the studies agreed with Bacon (1969) that the open-book examination makes straight the way to a greater concentration on ideas and concepts, on methods and development, whilst reducing the body of knowledge that needs to be remembered for an examination, and which will probably not need to be retained after the examination. (1969, p.363; quoted Francis, p.15) ${ }^{2}$ 
The body of Francis' article evaluated the findings from a pilot scheme initiated by The Associated Examining Board. The scheme set out to test the effectiveness of open book assessment in literature courses. It consisted of an alternative syllabus and open-book examination in English Literature at Advanced Level, and candidates' work in this syllabus was compared to the work of candidates who took the traditional syllabus and examination. Subject experts drew up a list of four criteria on which to judge the work of the two sets of candidates. These criteria were -

1. working knowledge of the text

2. understanding of the literary qualities of the text

3. perception and personal response to the text

4. formal presentation of work and the quality of written English (Francis, pp.17-18)

Subject experts were asked to grade marks on a scale A to F, according to their assessment of merit. In addition, students and teachers who took the alternative syllabus were asked to comment on the teaching and learning process.

Francis reports that in general, the alternative candidates attained a higher standard of achievement over all the four criteria above, with criterion 1 exhibiting the greatest differential, and criterion 3 exhibiting the least. He also reports that 'it was the candidates who achieved the high grades, that is the more able students, who appeared to benefit most from the open-book environment' (p.24). Francis also gives us some of the views of the participants in the experiment, and these give interesting insights into the practices of both teachers and students. The majority of teachers thought that open-book examinations had changed their teaching practice, so that they focused more on encouraging students' skills of literary analysis - the deep learning skills - as opposed to the more superficial skills of factual knowledge and crammed rote learning. Rather surprisingly, candidates reported that they still memorised details of the set texts, citing the need to locate details quickly in the text as a reason for still doing this. Most candidates also annotated their texts, which they were allowed to do. The annotation took various forms from simple underlining to marginalia to summaries and extended notes in longhand. Candidates prepared for the examination by a variety of methods - by repeated reading, writing model answers and identifying themes and issues in the texts that could be raised in examination questions. Having the texts to hand was a boost to their confidence, they felt, but students were wary of the complacency that the presence of the texts could engender. (pp.21-24)

These findings are illuminating, particularly for heavily text-based subjects . Francis' evaluation of the Associated Board's findings highlighted two key issues. First, if open-book examinations are to function as appropriate instruments of assessment, the objectives of the syllabus they assess ought to be at least re-considered and perhaps altered to match the new 
assessment environment. The Associated Board recognised this implicitly when they set an alternative syllabus which the open-book examinations assessed. Second, if the examination method is to succeed in allowing candidates to perform to the best of their ability, both students and staff must recognise that changes need to be made to their teaching and learning practice. This in turn involves staff reviewing their models of learning which they apply to the course they are teaching.

\section{Mnemosyne and the Law}

The key issue for legal academics is of course memory, for open-book examinations appear to absolve students from the drudgery of committing large tracts of the law to memory, to allow them to copy from cases and statutes and crib what others have written. Examinations thus become easier to pass; standards appear to fall; students' learning is perceived as shallower because less knowledge is being absorbed. Whether open-book examinations encourages what appears to be at first glance shallow learning is at least debatable - Francis' study showed that it is not the case, and that students' changed learning patterns demonstrated their sophisticated response to the new regime - but in the domain of legal studies there is a further dimension to the issue.

Memory has for long held a privileged place in legal education. If there has been resistance to the concept of open-book examinations among legal academics it rests on this point more than any other. The resistance is a cultural one stemming from the very roots of our European legal educational tradition. Indeed, the requirement to memorise law has influenced the ways in which it is ordered and delivered within the legal curriculum to such a deep cultural extent that we are scarcely aware of its power. This hegemonic tradition has involved students committing to memory large tracts of substantive law in order to demonstrate mastery over it. To enable law to be taught and learned rationally, academics divide and sub-divide it into zones and hierarchies. The enterprise is one familiar to all faculties of the academy of course, 'the generic one of presenting a discourse so as to make it amenable to understanding and memory: ... for "method is the chiefest help of memory, [and] instructions for memory, if they belong to any art, must needs be logical"' (Fraunce, 1588, quoted Goodrich, 1990, pp.32-3). Knowledge memorised becomes knowledge transferred, from lecture or text to student, and applied by student to problem question during assessment. By memorising the law, the tradition has it, students subsume law, become it, enter into the profession. ${ }^{3}$ Without the body of memorised text, law students cannot function as a member of a professional caste. The foundational nature of this experience, however - almost a rite de passage of sorts and powerfully experienced as such by students - is rarely made overt, and almost never discussed as part of the substantive legal curriculum. 
Many of the cultural assumptions we make today about memory and legal education are based on practices that began in medieval universities. Indeed, we can trace the central role of memory in legal education to the early role played by memory in pre-print cultures. Such cultures created highly elaborated semiotic structures based upon the primacy of memory. Thus, for Quintilian, memory was an essential component in learning, and its processes were embedded in and facilitated by the art of rhetorical division. In his practical guide, the Institutio, he recommends the use of punctuation - cola, commata and periodi - to divide up texts into clauses which can be more easily memorised; and he advocates the use of notae, short-hand marks and abbreviations. ${ }^{4}$ These marks were taught in medieval universities as a specific skill, the ars notataria, one that was also implicitly an ars memorativa, for memorial notae were often used as mnemonics for concording texts. Using the iconography of Christian devotional texts, memory was habitually described by writers on rhetoric as a storehouse, a treasure chest, dovecote, beehive, an Ark of Noah amongst many other metaphors. But these figures were used as mnemonics, dynamically and interactively: memory was regarded as an active synthesising and creative force. ${ }^{5}$ In medieval scribal culture, text was often formatted to enable a reader to memorise it and the style and form of legal texts in the middle ages was influenced by such mnemonic concerns. The Decretum, for example, was set out in divisions, which were referenced by a number followed by the introductory word or phrase of the referenced canon. ${ }^{6}$ We might compare the form of the Decretum to a modern statute or case report. The latter documents have rhetorical structures devised to enable a reader to understand key information and access it rapidly, but neither statute nor report is set out in a form, which would encourage mnemonic engagement with the text. $^{7}$

We can see the same concern for mnemonic taxis in medieval legal educational practice. The fifteenth-century Italian jurist Peter of Ravenna declared of his lecturing practice -

I daily read all of my lectures of Canon Law without a book; but if I should have a book before my eyes, I deliver the textual concordances and glosses from memory so that I should not seem to omit the least syllable. (quoted Carruthers, p.162) Peter's technique sounds paradoxical, to say the least. He 'reads' (his memory) without a book; and when he has a book to hand, he reads his memory because he trusts it more than the text. His words illustrate the difference between our print culture and a trained mnemonic method situated in the context of a scribal literary culture, for Peter mistrusts the possibly corrupt text and puts more faith in the highly elaborated structures of memory. In a print culture, of course, the situation is the reverse: the book dominates as the uncorrupted and objective source. 
In Glasgow University's Hunterian Museum there is a fine example of the primacy of memory in medieval university assessment, and its powerful legacy to Renaissance and modern legal education. Included in an exhibition of the university's history is a wooden chair called the Blackstone Chair, made around 1700. In the base of the chair is a block of black marble, and mounted on the chair-back, above the sitter's head, is an hourglass. Generations of students were called to oral examinations on this chair. At the start of the examination, the bedellus inverted the hour-glass and shouldered his mace, until the sand in the upper glass, hidden to the student but visible to the questioning masters, disappeared into the lower one, 'when he grounded his mace with the word 'Fluxit' ('It has passed through') and observed, 'Ad alium, Domine' ('Next, sir!')'. (Durkan \& Kirk, 1977, pp.93; 100)

But the procedure of oral examination goes back further than the chair itself. Durkan and Kirk suggest that the origin of the name of the Chair goes back to the practice in continental medieval universities of 'triers' or examiners expressing their opinion of a candidate: little black stones for ignorance, white ones for knowledge. In the fifteenth century Glasgow University, students who read for their bachelor degree in Arts (a type of foundation course, and a prerequisite for students who wished to study law) had to pass this oral examination before they were allowed to proceed to the next examination diet. The triers consisted of four masters, two internal (ad infra) and two external (ad extra). Each student was questioned closely on two categories of text - ordinary books (roughly the equivalent of our prescribed texts), and extraordinary books (recommended or suggested reading). They were asked to give definitions and expand on their applications. Again, there is evidence even at this early date that the examinations were timed. ${ }^{8}$

One can appreciate why memory and oral assessment dominated in a culture with relatively few texts available to students and masters; but that it lasted well into the print cultures of the Renaissance and modern periods is a more complex matter. ${ }^{9}$ Indeed, it has lasted until the present day in some sectors of university assessment, especially postgraduate thesis assessment. We can understand this ascendancy if we appreciate that the oral examination can be a thorough form of examination precisely because it is not merely a test of memory. Students need to be able to define and distinguish propositions, to express themselves cogently, to understand, memorise and recall strings of arguments and definitions in oral disputations, and above all to manipulate knowledge at will. All of these skills within the legal domain are lawyerly skills, in that lawyers practise them constantly in offices and in court, and they are revived in contemporary legal curricula as key skills, transferable skills and the like. 
These skills are highly rhetorical, however; and it is here that we must draw the contrasts between the mnemonic activities of medieval law students and the activities preparatory to examinations carried out by contemporary law students. Principally, in modern legal education, the curricular links between memory, rhetoric and the law are weak. This is a fairly broad generalisation, of course, but it is probably true to say that whereas medieval educationalists and jurists understood and worked within a complex mnemonic culture, we post-moderns have lost the strong links that existed then between memory, writing process and legal practice, and education. Our students are seldom trained to use mnemonic techniques in their reading; instruction in modern forms of legal rhetoric appears in most curricula, late on towards the professional training stage; while in our traditional closed book assessments substantive law eclipses other components. Nowadays, our law students are required to memorise in an educational environment and print culture that does little to support that mnemonic activity. The mysterious Other that students wrestle with in the examination hall is Mnemosyne, memory itself.

Moreover, many of the recent reforms in legal education, particularly in assessment and curriculum, have been grounded in the recognition that if, in the last half century or so, the production and exchange of legal culture and information has undergone remarkable change, so forms of teaching and assessment ought to adapt to accommodate this. All of the major reports on legal education have commented on the process of this change. In 1980 the Royal Commission on Legal Services in Scotland, for example, was critical of the heavy reliance placed on rote learning of statute law and leading cases in assessments, and recommended that this traditional dependence be reduced, especially with regard to problem-solving questions. It is clear from the wording of its recommendation that the Commission saw open-book examinations as no easy option for students, but as a more efficient way of assessing them according to the principles of practice-oriented learning. The Commission's recommendations regarding the professional practice of lawyers in 1980s, have relevance not only for lawyers, but also law-related employment in the late 1990s such as that of social workers, surveyors and trading standards officers:

We do not think that rote learning in such a framework is of particular value; in such circumstances a 50 per cent or 70 per cent success rate is considered adequate for examination purposes, but such a performance in professional practice would be unacceptable. Although some courses in some law faculties set examinations for which students will have access to statute and standard texts, much as they would expect to have in a professional firm, there is a strong case for requiring all students to sit at least some examinations on this basis; and we so recommend. The pass standard should be raised accordingly. ${ }^{10}$ 


\section{The Diploma in Trading Standards examination: a case-study}

The subtleties involved in designing and implementing open-book examinations can be illustrated by a case-study, that of the Diploma in Trading Standards (DTS) examinations. These public examinations are administered by the DTS Council through the Local Government Management Board (LGMB), and the candidates are trainee Trading Standards Officers (TSOs), employed full-time by local authorities and on block release to local higher education centres which teach the Part 1 and Part 2 exams of the Diploma. ${ }^{11}$ For the most part the candidates are mature students, including graduates (occasionally, LLB graduates). The three-year Diploma curriculum is postgraduate standard overall, and contains an unusual blend of areas of knowledge, including law, economics, statistics, quality assurance, science and materials, principles of measurement, professional practice, and enforcement and advice. The law components predominate, and comprise general constitutional and EC law, and in considerably more detail, consumer law and the more specialist law of Weights and Measures. This reflects the situation in Trading Standards practice: the body of legal information TSOs have to deal is not a small one, with approximately 45 statutes and over 1,000 sets of Regulations, Orders and Codes of Practice. Unlike full-time undergraduate students, the Diploma students work closely in their offices with the law upon which they are being examined. They bring to the classes a familiarity with the law arising out of their work with criminal procedure in trading standards enforcement, and their roles of consultants to traders and arbitrators in consumer disputes. The Diploma is thus a professional training course as well as an academic course.

If the curriculum is an interesting blend of the academic and professional, until recently the form of assessment in the law papers has been traditional - for the most part a series of threehour unseen examinations. Legal academics and TSOs set and mark the papers for these examinations, which contain the typical mixture of problem scenarios and questions requiring description of law. ${ }^{12}$ In 1994, however, for the first time in the history of the examination, candidates sitting the four law papers of the Diploma in Trading Standards were allowed to use statute books in the examinations.

\section{The DTS open book debate}

The decision to hold open-book examinations was first proposed publicly at a meeting of the Syllabus Review Group at Ambleside in 1991. This group consisted of legal academics and TSOs and members of the DTS Council. Later, because of concern expressed by lecturers at the teaching sites an initial meeting was held at Birmingham University and a further meeting at the LGMB centre in London to discuss implementation of the proposal. At the last meeting a vigorous debate ensued, at the end of which it was decided in principle that students would 
be allowed to use two copies of statute collections in the Diploma law examinations, and that the copies were to be 'clean' - that is, without sidelining, highlighting or annotation. The changes to assessment would be effected in the then current year: this meant that the DTS Part 2 students had completed nearly half of their 18 months-long course by the time they were informed of the change. It was also decided to review the success of the assessment format in the near future.

The central point of the debate concerned the practical implementation of a 'clean' or blank open book format. It was acknowledged that the two collections of statutes chosen as open book texts did not contain all the statutes used in the course - Weights and Measures Act 1985, Food Safety Act 1990, Medicines Act 1986, Agriculture Act 1970 and European Communities Act 1972 for example. ${ }^{13}$ In addition, subordinate legislation in Regulations and Orders, together with Codes of Practice and the like were not contained in the collections (this body of applicable subordinate legislation forms a substantial part of the DTS curriculum, for TSOs use it extensively in their work; and students are required to have a working knowledge of it). Moreover, the two collections of statutes are based on English law: no special provision was made for Scottish students, who would thus sit the examination at some disadvantage to English students.

Perhaps most significant in the wide-ranging discussion of open-book examinations was the absence of reference to the body of educational research carried out into open-book assessment. Francis found twenty references in 1982, and drew on the findings of eleven for his summary of the literature. None of this research literature found its way into the debate; nor was reference made to the wider context of educational research on assessment and memory and associated topics such as the nature of expertise, or the education of other professional groups. ${ }^{14}$ Legal academics as a group have in the past been notoriously uninterested in educational research and its practical application to the teaching of law. This debate could be said to be one example of a situation which required careful consideration of the existing research before deciding which version of open-book assessment - if any - would be appropriate to the needs of students. ${ }^{15}$

As a result the debate concerning the educational value of open-book assessment and its appropriateness to the education of TSOs was grounded on personal experiences of assessing students largely under a closed book system. Those who favoured blank open book assessment with no notation at all were of the opinion that if students were allowed to make notes on their texts, they would not memorise essential elements of legal rules. They held that the standard of the examination and of examinees would decline. A key argument against notation of open books thus rested on the primacy of memory: TSOs, it was argued, required 
to have memorised a considerable body of law because of the nature of their job. If they discovered anything suspicious while visiting retail premises for example, they had to know what to do there and then, otherwise returning to the office to check up on the law could give a retailer the opportunity to remove evidence.

This defence of blank open books was seen to be a persuasive one at the time, arguing as it did from the praxis of TSOs to draw apparently irrefutable conclusions about academic assessment of the knowledge required by a competent TSO. But it could be said that the argument misconceives the nature of law examinations and the part played by memory within it. First it equates the situation of the candidate in an exam with the situation wherein a TSO is confronted with a set of legal problems which he or she must solve instanter. At best, law papers primarily examine the skills of legal analysis, as these are presented perforce in an artificial environment. In the context of an LLB curriculum, for example, few legal academics nowadays would assent to the view that their exam questions are a direct preparation for the tasks of legal problem-solving which lawyers carry out in practice. ${ }^{16}$ Written exams are not real-life legal practice, nor are they a direct preparation for it. At best they can test a limited range of the skills of legal analysis. This view is borne out by research: some theorists have pointed to the problematic relations between theory and praxis in professional education, while others have adopted a more extreme position in declaring that content knowledge has little bearing on occupational performance ${ }^{17}$.

Secondly, learning to memorise the law is only one of the skills of legal analysis. It is impossible to analyse the law without a knowledge of basic legal principles, of course; and to apply legal principles to practical problems one requires a memorised structure or taxis of principles. But of itself and especially in the context of examined syllabi, rote learning can be a passive, inert rehearsal of information, which encourages docility in students. As a form of memorising, it can degenerate into frantic exam cramming, wherein facts are superficially rehearsed for the exam and then largely forgotten after it. ${ }^{18}$ It might be said in fact that apart from the artificial mnemonic systems outlined above (used by very few students), the most deeply encoded memory traces are a result of interacting with the world in a meaningful way. Law examinations, with their highly artificial constraints and environment do not test this type of memory well: they cannot take on the role of flight simulators for TSOs.

Indeed, it could be argued that the blank open book examination widens the gap between theoretical knowledge and praxis. This interface is problematic in education, particularly in professional courses such as the Diploma in Trading Standards. Frequently it appears as a question of transfer: namely, how does one effect transfer of knowledge from one domain or environment to another. The argument put forward by proponents of blank open book 
assessment (and it is close to the argument in support of traditional closed book assessment) is that memory-work is an essential component to the learning patterns of students: the absence of information in closed book examinations compels students to memorise legal rules and cases. Furthermore they claim that memorisation supports transfer of learning from one domain to another, for in attempting to understand and memorise the material, students make many passes through it, and thus understand it at a deeper level than they would otherwise.

This view has the merit of leaning on the indisputable point that students of law require to memorise basic legal principles. But it does not represent the whole story, and in parts is contradicted by a substantial body of phenomenographic and cognitive research into memory and learning, which tells us that learning happens not by recording information, but by interpreting it. Entwistle \& Entwistle, for instance, (1992) have cast doubt on examination questions which appear to test a student's conceptual understanding of a subject ('Explain the term 'duty of care' as used in the law of negligence', for example). They demonstrate that students can understand lecture notes without much active engagement with the ideas contained in the lectures, and without the ability to transfer this knowledge to other domains, or to use it to solve problems in novel situations.

In research into reading processes, memory is similarly contextualised within interpretive processes. Thus Kintsch pointed out that 'being able to recall a piece of information is not a sufficient condition for being able to actively utilize this information for some other purpose' (1986, pp. 841-51; 848). Kintsch explains the difference in terms of what he calls 'textbase' and 'situation model'. Readers who formed an adequate textbase performed well on memory tasks. They were able to reproduce the text, even to summarise it. But readers whose situation model - that is, their knowledge of the external context of the remembered text remained deficient, were unable to use the recalled text in tasks requiring inferential acts. As Kintsch says, 'there is an important difference between just remembering a text and learning from it to perform some kind of action' (1986, p.849). ${ }^{19}$

Taking a broader view of the research, if the link between memory and the ability to perform well in problem-solving is no longer seen as a direct one, there are claims that high levels of competence in expert performance result from the interaction between knowledge structure and processing abilities. Three cognitive theories of learning are relevant here, all of them attempting to describe how learning takes place and how transfer is effected in expert performance. In the first, learning is seen as a process of knowledge construction, not knowledge absorption. This theory focuses on the constructive mental activity which takes place in the learner, and emphasises that meaning is 'rooted in, and indexed by, experience' rather than the teacher-centred bias and mastery learning of many classical instructional 
strategies (Duffy \& Jonassen, 1992, p.4). ${ }^{20}$ The second theory states that learning is knowledge-dependent and knowledge-driven. In this theory learners use current knowledge to understand new knowledge by using elaborative processes and forming relationships between items of old and new knowledge. The key to expert performance, according to this theory, lies in identifying and learning effective elaborative processes. ${ }^{21}$ The third theory (especially relevant to professional and vocational learning) concerns itself with situated knowledge, and posits that both knowledge and skills cannot viably be separated from the social and mental context in which they are practised. If learning, and especially transfer of learning is to be effective, then it could be argued that it ought to be organised so as to reflect the conditions of practice (Brown et al, 1989).

In its operation and effect, the blank open book examination cuts across the bows of all three theories. This type of assessment presents students with texts they do not 'own' - the text stands resolute and alienating in its blankness, without the glosses, marginalia, post-its and the many other devices of idiosyncratic ars notataria which contemporary students and professionals alike use to create from a text their own personal webs of meaning. This distance may serve, as we shall see, to heighten, not reduce, students' anxiety about assessment. Furthermore, the text itself is not a situated text: it could be argued that it does not contribute effectively to the students' construction of knowledge. And if it does not enable a student to solve a legal problem in an assessment it can become, for the student, part of the problem of learning the law. ${ }^{22}$

\section{Student response to the blank open book examination}

The response of my own students studying for the DTS Part 2 examinations was significant. ${ }^{23}$ They were dismayed by the decision of the DTS to hold blank open book examinations, and would have preferred a truly open book context in which they could use notated texts, as did the students in Francis' study.

One might have expected that the change from traditional unseen examination to open-book would involve significant change in patterns of student learning. In reality, little change took place; and this could be attributed to the form of the blank open-book assessment. As was pointed out above, the open books did not contain all the necessary statutes and Regulations. Moreover, students still felt they had to memorise the 'clean' statutes if only because they were unsure whether they would have time in the examination to flick through the collections searching for particular sections. They also recognised that the structure of the statute together with definitions and cross-references still had to be learned, and for them the simplest way to do this was to memorise sections and their contents. They were not prepared, halfway 
through the Part 2 course, to change methods of examination preparation, which had served them well in past traditional examinations.

Their attitude here is revealing, if at first glance paradoxical. They distrusted the accessibility of the statutes and preferred to treat the open-book exam as if it were a traditional assessment. Their distrust of text both parallels and contrasts with that of Peter of Ravenna, quoted above. The medieval jurist and twentieth century students would - for very different reasons - prefer to use their memories; but given the free choice of blank text or notated text, the students unhesitatingly chose the latter. They were in fact treating the blank texts as part of the assessment's difficulty, not as an aid to solving problems.

If students distrusted the new regime, it was partly because it gave confusing signals to them. For example, regulations, which follow the Consumer Protection Act 1987, were not included in the prescribed texts, but the CPA itself was. Did this mean, students wondered, that they had to memorise the minutiae of the regulations while leaving the general and fundamental principles of Consumer Safety legislation unmemorised? This could lead to the situation where, because a student may have forgotten a regulation, an examiner could be unable to discern whether a student had understood and could apply the principles of the CPA. Indeed, there is merit in the argument that the procedure should have been reversed: it might have been more appropriate to allow access to the regulations in open book form, and test students' understanding of the general principles of Consumer Safety law, its fundamental definitions, rights, obligations, remedies and defences. These, after all, change little over a span of years, while the regulations may change more frequently. In discussion with students on the matter it was clear that they considered the style of the DTS open book examination, and therefore their learning patterns, had been dictated by the availability of published statute collections. These collections do have the merit of imposing consistency of textual access upon all students sitting the examinations. Nevertheless, students sensed - without saying so in as many words - that there was an absence of consideration of the meta-curricular planning issues that ought to guide the diagnostic assessment of cognitive skills in domain expertise.

A comparison with the responses of students in Francis' study is revealing. There, students adapted their traditional learning patterns and individual styles to study more effectively in the new environment of the Alternative syllabus and open book assessment. They did so because the syllabus encouraged them to do so, while the completely open nature of the assessment gave them the opportunity to plan, construct and demonstrate situated learning. Furthermore, the climate of the syllabus acknowledged the complexity of the relationship between learning and assessment, its inherently problematic nature, and accommodated it, while the 'clean' blankness of the DTS examination implicitly denied it. 


\section{Alternatives to blank open book assessment}

So far, we have been examining one open-book model of assessment carried out in the DTS examinations. But are there alternatives to it?

Many law courses now allow students to take their notes into the examination room, with whatever annotation they care to make upon them. One example will suffice. I taught a firstyear module in Legal Skills, in the University Diploma in Legal Studies at Glasgow Caledonian University, in which students worked on legal research, reading and writing skills. In the legal writing skills unit students focused largely on drafting discursive and problem-solving essays, and on achieving an understanding of the contexts of different legal genres and texts. Assessment for the legal writing unit of the module was a three-hour entirely open-book examination consisting of unseen drafting and critique activities. In the first year that the module ran, a short questionnaire was issued to all students (thirty-three in total) directly after the exam, asking for their feedback on what was for all of them a new form of assessment. The results were an overwhelming endorsement of the assessment method. Thirty-one students felt that the examination questions were an appropriate assessment of what they had learned during the module, and the same number again approved the entirely open-book nature of the assessment. The following comments were indicative of their views:

Essay type exams, in my view, provide a better view of student ability. In reality, when working, law graduates will work with books, etc.

This type of exam is good in that it enables you to see just what you have learned throughout the year

Able to concentrate on format of essay rather than just facts. Didn't have to fill head with facts.

Makes you feel more confident even if you didn't use books in the exam. More relaxing, not so much pressure. Could sleep the night before!

These comments support Francis' view of open book assessment quoted above. Moreover it was clear that the relationship between the module syllabus and assessment was an essential component of this approval by students: they used the same materials in their learning as in their assessment; they had to take responsibility for deciding how to prepare for the examination; rote-learning was minimised; deep learning and understanding was prioritised. 
Alternatives to the DTS Council's blank open book proposals do exist, therefore; but we can go further and look to the broader educational context of open-book assessment. Within the last few decades, the rationale behind memorising great tracts of black letter law has been questioned, both in its theory and practice. Foremost among the critics has been the skillsbased learning movement. The movement is a broad church, unified by its dissatisfaction with the narrow base of traditional teaching styles, and relying at least in part on an interdisciplinary approach to teaching and learning, including cognitive psychology, phenomenography, situated learning, clinical legal skills education, contextual studies, and systematic instructional design to name but a few. ${ }^{24}$ Instead of dividing and sub-dividing zones of substantive law, this movement tends to analyse the skill components that underlie learning, and emphasise these instead of the weight of memorised black-letter law. It also argues that integration of knowledge and skill, and transference of legal skills are crucial principles within the legal curriculum. David Barnhizer reveals the link when he quotes David Ausubel as being for him the origin of the idea of a cognitive conceptual structure:

Existing cognitive structure, that is, an individual's organisation, stability, and clarity of knowledge in a particular subject matter field at any given time, is the principal factor influencing the learning and retention of meaningful new material. ... When we deliberately attempt to influence cognitive structure so as to maximise meaningful learning and retention we come to the heart of the educative process. (Barnhizer, 1979, p.82, quoting Ausubel 1969) $)^{25}$

The new movement is learner-centred rather than corpus-based (Adams \& Brownsword, 1992; Brayne, Duncan and Grimes, 1998). It sites expertise not in substantive knowledge of law but in what the student does with legal information and within the structures of legal process. Memory work plays a role here, but it is not pre-eminent. It is often assessed as merely one of many components of lawyerly skill and knowledge. The movement frequently sees the task of legal education holistically, as one that fuses professional and academic stages, skills and substantive knowledge. It espouses 'a combination of knowledge, skills and attitudes that cannot be separated out into separate spheres and learnt in separate processes' (Jones, 1989, p.187). It also uses less traditional forms of assessment: self- and peerassessment; video and role play, and entirely open book examinations.

Two examples of the above are the approach adopted by the Faculty of Law at the University of Maastricht, and the Professional Legal Training Course run by the Law Society of British Columbia. In the former, the Law Faculty took the lead offered by its sister Faculty of Medicine and adopted the influential approach of the Faculty of Medicine, McMaster University, in Hamilton, Ontario. The Law Faculty's approach at Maastricht is characterised 
by interdisciplinary education, problem-oriented education arranged thematically, skills training and, in the area of assessment, examinations and skills tests (Moust \& Nuy, 1987; Cruickshank, 1996, pp.215-16). In the British Columbia course, students were given 'systematic and concentrated training' in skills (Jones, 1989, pp.176-7). The course was assessed by five components - four skills assessments and an open-book examination. In this examination students could use 'Practice Materials, Activity Plans, copies of statutes, Law Society Rules and Handbook, and their own notes and texts' (Jones, 1989, p.184).

These approaches are quite different from that of the blank open book approach in the DTS law examinations. While studying in that curriculum, students were already working in a context-rich professional office environment which inducted them into the procedural knowledge and skills required of a TSO. When it came to assessment of legal knowledge and procedures, however, the blank open book examination altered the familiar boundaries of closed book assessment while still denying students the tools of their situated professional practices.

\section{Conclusion}

A debate about assessment, particularly in a curriculum as close to professional practice as is the Diploma in Trading Standards, inevitably involves issues such as learning objectives, teaching and learning styles, administrative practicability and the like. Beneath these lie deeper issues: models of teaching and learning, and views of what the profession does and how best to prepare its practitioners. At an even more foundational level, though, lie the meta-issues of theory and practice, and the relations between the two as these are interpreted by both universities and professional regulatory bodies. What do they consider to be the relations between educational theory and practice? What is their view of the theory of professional practice as applied to the experience of lived practice? If educational theory and practice are to be effective in transferring students' knowledge and skills to the sphere of practice, then these issues must be given serious attention. ${ }^{26}$

For several decades now there has been wide-ranging discussion of just these questions. Researchers such as Schön, Argyris, Eraut, Boud and many others have been developing a sophisticated analysis of the ancient dualism between theory and practice. According to Schön, the traditional 'technical-rationality' model, as he terms it, equates theory with knowledge and principles, and practice with merely 'instrumental problem-solving' (1987). This traditional model has little to say about transference or transformation of theory into practice: it is simply not seen as problematic. For Schön, though, this issue is deeply problematic. He reveals that practice rarely deals only with problem-solving: it also has to 
construct problems in the midst of uncertain and ambivalent situations where such factors as agency, evidence, means and ends and probabilities are constantly shifting and perplexing variables. In these situations, the traditional notion of applying theory to practice becomes at least unhelpful, at times an obstruction to effective practice. In such circumstances theory about practice can, as Eraut points out, attain an oppressive hegemony within a profession, and may become a body of prescriptive concepts which, though widely circulated, and attaining the status of revered shibboleths, 'offer no practical advantage' to professional practice (Eraut, 1985, p.125; 1994).

Over against the dualistic confrontation of theory and practice, Schön constructs an 'epistemology of practice', a transactive model where knowledge or theory is constructed out of practice or experience, which in turn reacts with previously held knowledge of theory and practice. Practitioners do so by engaging in reflection-on-action and reflection-in-action. The former is the less effective form of reflection upon action, coming as it does post factum. The latter, however, is a powerful method of engaging in analysis of practice through the mediation of theory. In turn it can generate fresh knowledge and theory which is practicederived, but which enacts a dialectic with the content knowledge of formal theory.

Schön's model of the relationship between theory and practice, elaborated, glossed and critiqued by many others in the field, is one example of the sophisticated analysis of the debatable lands between theory and practice. ${ }^{27}$ Any analysis such as Schön's has implications not only for the models of teaching and learning we hold, but also for the learning objectives we set and styles of teaching and learning we practise (Usher \& Bryant, 1987, pp.205-6). It also directly affects our preferences for assessment. If, for example, we act according to a technical-rationality model in which doctrine and theory is separated out from and applied to practice, our preferences for assessment are liable to be for closed rather than open book; and for blank open book rather than notated open book. If we hold by a model such as Schön's reflective practitioner, our preferences will be for assessment which contextualises legal doctrine and theory as much as possible in what Vygotsky defined as the zone of proximal development (1978). But whatever model we espouse, and this is the most important point to arise from the open book debate outlined above, it is essential that we are clear about our choices and their implications, not only for our educational practice, but for the students who, after all our assessments and gradings are over, will be faced with the ever-present challenge of applying theory to practice in their own right. What role models, we might ask ourselves, do our learning models and forms of assessment give them for their task of life-long learning?

On a broader plane, the DTS open book debate exemplifies the contemporary shift in relations between the academy and professional bodies. ${ }^{28}$ For legal academics, the situation 
outlined in footnote 15 above is altering rapidly. New conditions of service and initiatives in teaching and learning (the rise in student numbers, the Funding Councils' Teaching Quality Assessment, QAA, benchmarking, the appearance of books, journals and websites specialising in legal education, and the Law Courseware Consortium TLTP amongst many factors) have begun to engineer change, to the extent that legal educational theory is now a more prominent feature in the curricular landscape of most university law schools. As legal academics become more aware of the historical, cultural and educational resonance of their heuristics and assessment methods, so their dialogue with professional bodies over the nature of professional education, its content and delivery grows in sophistication. Such a dialogue has always existed, of course; but in future it will become increasingly influenced by research from other, adjacent disciplines, and by the debate regarding quality in education. ${ }^{29}$ As a consequence the nature of the consensus of aims and methods which had existed between the academy and professional bodies is being fashioned anew. If carried out sensitively by both sides, this process will strengthen the essential relationship between the two and, one would hope, improve the quality of education for our students.

\section{Acknowledgements}

I would like to express my gratitude to Mr Tom Philpott, Trading Standards Officer Training Unit, and Ms Jayne Williams, lecturer in Consumer Studies Dept, Glasgow Caledonian University for their helpful comments on parts of this article; and to the anonymous reviewers for their constructive criticism.

\section{References}

ADAMS, J.N. \& BROWNSWORD, R., (1992) Understanding Law (London: Fontana) ANDERSON, J.R. \& FINCHAM, J.M., (1994) Acquisition of procedural skills from examples, Journal of Experimental Psychology, 20, 6, 1322-40

AUSUBEL, D. (1969) Cognitive structure and the facilitation of meaningful verbal learning, Contemporary Issues in Educational Psychology, 189-211

BACON, F. (1969) Open Book Examinations, Education and Training, September, 358-369

BARNHIZER, D. (1979) The clinical method of legal instruction: its theory and implementation, Journal of Legal Education, 30, 67-148 
BARRETT, B. (1990) What should we be learning about legal education? The Law Teacher $24,1,3-15$

BRAYNE, H., DUNCAN, N. and GRIMES, R. (1998) Clinical Legal Education: Active Learning in Your Law School (London, Blackstone Press)

BRIGHT, S. (1991) What, and how, should we be teaching? The Law Teacher, 25, 1, 1-18 BROWN, J.S. et al., (1989) Situated cognition and the culture of learning, Educational Researcher, 18, 32-42

BROWNSWORD, R. (1996) Where are all the law schools going? Journal of the Association of Law Teachers, 30, 1, 1-25

CARRUTHERS, M. (1990) The Book of Memory: A Study of Memory in Medieval Society, (Cambridge, Cambridge University Press, Cambridge Studies in Medieval Literature) CHI, M.T.H. \& BASSOK, M. (1989) Learning from examples via self-explanations. In Resnick, L. ed. Knowing, Learning and Instruction: Essays in Honor of Robert Glaser (New Jersey, Hillsdale) pp.251-83

COLE, A.L. (1997) Impediments to reflective practice: towards a new agenda for research on teaching, Teachers and Teaching: Theory and Practice 3, 1, 7-27

CRUICKSHANK, D. (1996) Problem-based learning in legal education. In Webb, J. \& Maughan, C. eds Teaching Lawyers' Skills (London, Butterworths)

DUFFY, T.M. \& JONASSEN, D.H. (1992) eds Constructivism and the Technology of Instruction: a Conversation (Hillsdale, New Jersey, Lawrence Erlbaum)

DURKAN, J. \& KIRK, J. (1977) The University of Glasgow 1451-1577 (Glasgow, University of Glasgow Press)

ENTWISTLE, N. (1992) The Impact of Teaching on Learning Outcomes in Higher Education: A Literature Review (London, CVCP/USDU)

ENTWISTLE, A.C. \& ENTWISTLE, N. (1992) Experiences of understanding in revising for degree examinations, Learning and Instruction, 2, 1-22

ENTWISTLE, N. \& ENTWISTLE, A. (1991) Developing, Revising and Examining Conceptual Understanding in Degree Courses: The Student Experience and its Implications (Edinburgh, University of Edinburgh)

ENTWISTLE, N. \& MARTON, F. (1994) Knowledge objects: understandings constituted through intensive academic study, British Journal of Educational Psychology, 64, 161-178 ERAUT, M. (1985) Knowledge creation and knowledge use in professional contexts, Studies in Higher Education, 10, 117-37

ERAUT, M. (1994) Developing Professional Knowledge and Competence (London, The Falmer Press)

FEBVRE, L. \& MARTIN, H-J. (1984) The Coming of the Book: The Impact of Printing 1450-1800, eds Nowell-Smith, G. \& Wootton, D., trans. Gerard, D. (second edition, London, Verso) 
FRANCIS, J. (1982) A Case for open-book examinations, Educational Review 34, 1, 13-26 FRAUNCE, A. (1588) Lawiers Logike (London)

GLASER, R. (1984) Education and thinking: the role of knowledge, American Psychologist, 39, 93-103

GLASER, R. (1986) On the nature of expertise, in Klix, F. \& Hagendorf, H., eds, Human Memory and Cognitive Capabilities: Mechanisms and Performances (North-Holland, Elsevier Science Publishers B.V)

GOLD, N. (1989) The Professional Legal Training Program: towards training for competence, The Advocate, 10, 1-12

GOODRICH, P. (1987a) Legal Discourse: Studies in Linguistics, Rhetoric and Legal Analysis (London, Macmillan)

GOODRICH, P. (1987b) Psychoanalysis in legal education: notes on the violence of the sign. In Kevelson, R. ed Law and Semiotics, vol 1, (New York, Plenum Press)

GOODRICH, P. (1990) Languages of Law: From Logics of Memory to Nomadic Masks, (London, Weidenfeld \& Nicolson)

GRABINGER R.S. \& DUNLAP, J.C. (1995) Rich Environments for active learning: a definition, Association for Learning Technology Journal, 3, 2-37

GRESTY, G. (1997) Delivering the professional qualification into the millennium: the review of the Diploma in Trading Standards, Trading Standards Review, March, 12-13

HEALY, A.F. \& BOURNE, Jnr, L.E. (1995) eds Learning and Memory of Knowledge and Skills: Durability and Specificity (London, Sage)

JOHNSTONE, R., PATTERSON, J. and RUBENSTEIN, K. (1998) Improving Criteria and Feedback in Student Assessment in Law (London, Cavendish)

JONES, P. (1989) A skills-based approach to professional legal education - an exemplary case, Journal of the Association of Law Teachers, 23, 2, 12-24

KINTSCH, W. (1986) Memory for prose. In Klix, F. \& Hagendorf, H., eds, Human Memory and Cognitive Capabilities: Mechanisms and Performances, (North Holland, Elsevier Science Publishers, B.V)

KISSAM, P.C. (1989) Law school examinations, 42 Vanderbilt Law Review 433-472 KLEMP, G.O. (1977) Three Factors of Success in the World of Work: Implications for Curriculum Planning in Higher Education (Boston, McBer)

LANDOW, G. (1992) Hypertext: The Convergence of Contemporary Critical Theory and Technology (Baltimore, The Johns Hopkins University Press)

LAW SOCIETY (1995) Announcement on Qualifying Law Degrees (London, Law Society of England and Wales)

LE BRUN, M. and JOHNSTONE, R. (1994) The Quiet (R)evolution: Improving Student Learning in Law (Sydney, The Law Book Company)

MACKIE, K. (1990) A strategy for legal education research, The Law Teacher, 24, 1-17 
MAHARG, P, McDONNELL, T., STONELY, P. (1997) The Review of the Diploma in Trading Standards, unpublished contract research (LGMB/ITSA)

MOUST, J.C. \& HUY, H.J. (1987) Preparing teachers for a problem-based, student-centered law course, Journal of Professional Legal Education, 5, 19-25

NEWBLE, D.I., JAEGER, K. (1983) The Effect of Assessments and Examinations on the Learning of Medical Students, Medical Education, 17, 25-31

NORTH, R., (1650/1824) A Discourse on the Study of the Laws (London, T. White) OLSON, D.R. (1994) The World on Paper: The Conceptual and Cognitive Implications of Writing and Reading (Cambridge, Cambridge University Press)

PALIWALA, A. (1999) Learning in Cyberspace, BILETA Annual Conference, BILETA 99: Cyberspace 1999: Crime, Criminal Justice and the Internet: An International Conference, March 1999, http://www.bileta.ac.uk

PEARCE, D., CAMPBELL, E., and HARDING, D. (1987) Australian Law Schools: A Discipline Assessment for the Commonwealth Tertiary Education Commission: A Summary and Vols 1-4 (Canberra, Australian Government Publishing Service)

PIRIE, A.J. (1987) Objectives in legal education: the case for systematic instructional design, Journal of Legal Education, 37, 576-97

QUINTILIAN, M.F. (1920-24) The Institutio Oratorio of Quintilian, trans. by H.E. Butler, 4 vols (London, Heinemann)

RAMSDEN, P. (1992) Learning to Teach in Higher Education (London, Routledge) Royal Commission on Legal Education in Scotland (1980), Command Papers 7846 SAMPFORD, C. (1998) Rethinking the core curriculum. In Goldring, J., Sampford, C., Simmonds, R., New Foundations in Legal Education (London, Cavendish) SCHÖN, D. (1987) Educating the Reflective Practitioner: Toward a New Design for Teaching and Learning in the Professions. (London, Jossey-Bass Publishers)

THEOPHILIDES, C. and DIONYSIOU, O. (1996) The major functions of the open book examination at the university level: a factor analytic study, Studies in Educational Evaluation, 22, 2, 157-70

THOMAS, P. (1986) The Structures and Stability of Learning Approaches, unpublished PhD thesis, University of Queensland, Australia.

TODDINGTON, S (1996) The emperor's new skills: the academy, the profession and the idea of legal education. In Birks, P.B.H., ed. What are Law Schools For? (Oxford, Oxford University Press)

TONFONI, G \& RICHARDSON, J.(1994) Writing as a Visual Art, (London, Intellect) TWINING, W. (1994) Blackstone's Tower: The English Law School (London, Sweet \& Maxwell)

TWINING, W. (1997) Law in Context: Enlarging a Discipline (Oxford, Clarendon Press) 
USHER, R.S. \& BRYANT, I (1987) Re-examining the theory-practice relationship in continuing professional education, Studies in Higher Education, 12, 2, 201-212 VYGOTSKY, L.S. (1978) Mind in Society: the Development of Higher Psychological Processes, M. Cole et al., eds, (Cambridge MASS. Harvard University Press) WEBB, J. \& MAUGHAN, C. (1996) eds Teaching Lawyers' Skills (London, Butterworths)

\footnotetext{
${ }^{1}$ Brownsword (1996) inquires along similar lines when he states that 'whilst the views of the professional
} bodies obviously merit respect, academic lawyers need an independent foundation for their view of the essential mission of the university law school' (p.5). For him, the dichotomy between professional bodies' 'foundational objectives' such as that contained in the Law Society's Announcement on Qualifying Degrees and law school mission statements requires law schools to return to first principles, to the purpose of a university and a law school (ibid, pp.4-5).

${ }^{2}$ A point raised by Theophilides \& Dionysiou (1996)

${ }^{3}$ This is a common trope in legal educational texts. See for example North (1650/1824) - '[students] must not only read and talk, but eat, drink and sleep law' (p.7)

${ }^{4}$ Institutio Oratoria, I, I, 36

${ }^{5}$ For a subtle analysis of this, see Carruthers (1990) pp.36-7; 112-13. For an example of such mnemonic figures analysed by Carruthers, see her description of Hugh of St Victor's 'De arca Noe morali' (pp 208-11).

${ }^{6}$ Ibid, p.99. As Carruthers points out, the development of the prose cursus, 'used in administrative and legal writing especially, is probably a related aid for the trained notarius' (p.317). Goodrich (1987a) raised the general historical question of the loss of the rhetorical disciplines in Part II of his book: "[t]he history in question is that of the repression and exclusion of rhetorical and "topical" contingencies, largely coincident with the rise of the empiricist and rationalist philosophies of the seventeenth century' (p.88). Goodrich goes on to trace within the history of rhetoric the loss of 'the study of the historicity of discourse', its separation from philosophy and its condemnation to 'the triviality of the purely verbal' (p.107)

${ }^{7}$ This could be said to apply to the physical form of the book as well as layout of the text. As George Landow and many others have pointed out with regard to early European publishers, the pagination, tables of contents, and indices which we take for granted in printed books took approximately a century to develop after the introduction of printing. As is the case with alphabetisation, the function of such indices is primarily that of information retrieval, not the mnemonic retrieval characteristic of manuscript culture. The process of historical change in reading habits brought about by this fundamental shift from mnemonic recall to information retrieval is well described in Landow (1992), pp. 30-31; 54-56, and 188-89

${ }^{8}$ According to Durkan and Kirk, Students also had to give an undertaking before the examination started that if they received black stones from the masters they would not attack them or otherwise injure them ...

${ }^{9}$ For illustration of the close links between universities and early print cultures, see Febvre \& Martin (1984) chapters $4 \& 8$. For a discussion of the effect of print culture on the relations of writing and memory, see Olson (1994) 
${ }^{10}$ Vol 1, 16.24. This has been echoed by key reports since then throughout common law jurisdictions. See, for example, Pearce et al (1987) In recommending particular forms of assessment the Hughes Commission went further than the Ormrod Committee, which had already 'encouraged innovation and experiment in respect of curriculum, teaching methods and research' (Twining, 1994, p.37)

${ }^{11}$ The LGMB is now the Improvement and Development Agency for Local Government

12 There are a number of exceptions to this traditional assessment: papers 12 and 13, which contain strong elements of practice-based law, two workbooks, and the project which students are also required to submit, are based firmly upon practice-based issues

${ }^{13}$ Later it was agreed that students would be permitted to take 'clean' (ie unannotated) copies of statutes into the examination, together with a copy of the Code of Practice for Traders on Price Indications. However, this caused particular difficulties for students as regards amended legislation (I am indebted to Jayne Williams for this information).

${ }^{14}$ On the subject of expertise, for example, see the review article by Glaser, Robert, (1986). Glaser's list of twenty-four summary propositions (pp.926-8) is a good general and historical introduction to the cognitive research base on the interaction between knowledge structure and processing abilities.

${ }^{15}$ Barrett notes that in a conference paper William Twining observed that in the debates on professional legal competency and training, "'almost none of the protagonists have any competence in educational theory."' (1990, p.5) As Barrett goes on to point out, 'debates on curriculum content have hitherto given relatively little consideration to the learning process as opposed to identifying the range of information to be imparted' (p.6). See also Bright (1991), who points out that the 'traditional approach [to teaching and learning law] is coupled with, and may be explained by, the absence of serious epistemological debate on law teaching' (p.11). Mackie (1990) commented that 'there is wide agreement that legal education research has presented a fairly bleak picture in terms of its quantity or its impact on educational practice' (p.132). As a result of this historical lack of interest shown by legal academics in legal education as a serious legal topos, students exhibit the same apathy. Peter Goodrich has pointed out that 'there are in all probability few topics of controversy that are of less interest to their recipients than the discussion of legal education is to the students of law. Education is a given' (p.195). ${ }^{16}$ See, for example, Sampford (1998), quoting Flinders University of South Australia Law Handbook 1997: '"No LLB programme can or should aspire to produce a graduate who is immediately a 'complete' lawyer"” (p.130)

${ }^{17}$ See for example Eraut, M. (1985), and Klemp, (1977)

${ }^{18}$ An interesting analogy for the comparison between rote learning and thinking was made by Marvin Minsky An idea with a single sense can lead you along only one track. Then, if anything goes wrong, it just gets stuck, a thought that sits there in your mind with nowhere to go. that's why, when a person learns something 'by rote', that is, with no sensible connections, we say that they 'don't really understand'. Rich meaning-networks, however, give you many different ways to go: if you can't solve a problem one way, you can try another. True, too many indiscriminate connections will turn a mind to mush. But wellconnected meaning-structures let you turn ideas around in your mind, to consider alternatives and 
envision things from many perspectives until you find one that works. And that's what we mean by thinking!

Tonfoni \& Richardson (1994), p.15 (Foreword by Marvin Minsky)

${ }^{19}$ See also Anderson \& Fincham (1994), p.1322: '[The] view that declarative knowledge was a prerequisite to procedural knowledge has been criticised'. Anderson and Fincham then go on to discuss the body of literature, inter alia Berry \& Broadbent, who show that 'subjects can learn to successfully manipulate a rule-based system but cannot consciously state the rules. They interpret this to mean that procedural knowledge is acquired without first going through declarative knowledge'. A similar point has been made by others with regard to skill learning. As one recent book on the subject has it, '[h]ighly practised skill learning will be durable when the test of retention embodies the procedures employed during acquisition' (Healy \& Bourne, 1995)

${ }^{20}$ Duffy \& Jonassen (1992) p.4. They draw upon a number of different cognitive learning theories, especially situated cognition - see Brown et al., (1989)

${ }^{21}$ See for example Glaser (1984); Chi \& Bassok (1989)

${ }^{22}$ Though they do not discuss open book examinations in detail, Le Brun \& Johnstone (1994) make a similar point regarding other aspects of written exams. They criticise the 'objectivism' of this assessment, quoting Kissam (1989): 'The objectivism of law school examinations allows [us] to limit [our] engagement with both the teaching and evaluation of [our] students. The marked discontinuities between classroom work and examination work and the use of quantitative methods to ... grade law school examinations are the primary means by which we achieve this disengagement' (p.204). Curiously enough, as Le Brun and Johnstone point out, again quoting Kissam, there is more resemblance between the informational structures of examination answers written by students and oral communications than there is between the examination answers and the variety of written genres used in legal practice (p.205)

${ }^{23}$ Student response was articulated in action research interviews carried out with members of the class.

${ }^{24}$ The literature is too substantial to attempt even a representative sample here, but the following are illustrative. Le Brun \& Johnstone (1994), Twining (1997) Webb \& Maughan (1996) Brown et al., (1989), Barnhizer (1979), Barrett (1990), Pirie (1987), Grabinger \& Dunlap (1995), Paliwala (1999)

${ }^{25}$ Ausubel (1969), p.199

${ }^{26}$ Though I do not share his conclusions, Stuart Toddington (1996, p.82) has described this point well when he writes that ' $[\mathrm{w}]$ hat constitutes good practice is not something which is automatically given in simple experience of a practice; it is a form of theoretical understanding through which we interpret and evaluate our experience'

${ }^{27}$ For a thorough analysis of the application of Schön's model to legal education see Jones (1996). Recent attempts to clarify the numerous re-definitions that Schön has undergone are summarised in Cole (1997) pp.1113

${ }^{28}$ The DTS Council recently undertook a comprehensive review of professional education of TSOs. The contract research, funded by LGMB and ITSA (Institute for Trading Standards Administration, the professional body for Trading Standards) was a UK-wide review of the education and training of Trading Standards Officers which focused on the current structure and delivery of the current Diploma in Trading Standards, and the 
possible models of future structure and delivery. It was conducted by Glasgow Caledonian University and Stonely Consultants (Maharg et al 1997). Copies of the report are available from the Improvement and Development Agency for Local Government, or from the Chief Executive of the Institute of Trading Standards. See Gresty (1997) for a summary of the findings. Amongst our key recommendations was that the curriculum structure of the new Diploma qualification should be built upon an integrative view of professional knowledge and skills; learning contracts, workbooks and problem-based learning should be implemented to facilitate transfer of learning between academic and work-based learning; evaluation instruments should follow teaching and learning forms and criteria, not vice versa; and that procedures should be designed which ensured that there was a genuine partnership in learning and teaching between all the relevant interested parties: students, universities, LGMB, DTS Council, ITSA and local authorities.

${ }^{29}$ In saying this I do not underestimate the part that economics and finance has to play in the provision of legal education, nor the part that financial provision has to play in the Funding Council's Quality Assessments. See Twining (1994), pp.41-2.

The theoretical literature on the quality debate is considerable, and a number of student and staff development units are specialising in this field. See for example the Centre for Research on Learning and Instruction at the University of Edinburgh. Amongst their many publications relevant to this point are Entwistle \& Entwistle (1992), Entwistle \& Entwistle (1991), Entwistle \& Marton (1994). 